\title{
Entre o Trabalhador e o Vagabundo: Produção de Masculinidades na História da Saúde no Brasil
}

\author{
Helen Barbosa dos Santos*, 1 \\ Orcid.org/0000-0002-7732-3647 \\ Henrique Caetano Nardi ${ }^{1}$ \\ Orcid.org/0000-0001-6058-1642
}

${ }^{1}$ Universidade Federal do Rio Grande do Sul, Porto Alegre, RS, Brasil

\section{Resumo}

A Política de Atenção Integral à Saúde do Homem (PNAISH) emerge em 2009, colocando como objeto de atenção o corpo social masculino. Tendo em vista que a saúde dos homens é uma temática atual nos estudos de gênero, buscamos retomar os principais movimentos de produção social de masculinidades atravessados pela medicalização em distintas conjunturas históricas. Para tanto, apoiamo-nos em operadores conceituais pós-estruturalistas que buscam tomar as masculinidades como frutos de determinados contextos caracterizados por relações de saber-poder e de ênero, além de outros marcadores sociais. A análise aponta para as condições de possibilidade que conduziram determinadas masculinidades ao campo da abjeção por meio da marcação racial e pelo dispositivo do trabalho enquanto estratégia de poder para a medicalização do corpo social masculino. Nesta seara, a versão brasileira das masculinidades transita pela linha limítrofe entre o trabalhador e o vagabundo, linha essa traçada por mecanismos de medicalização e criminalização operando concomitantemente.

Palavras-chave: Masculinidades, saúde do homem, interseccionalidades.

\section{Between the Worker and the Vagabond: Production of Masculinities in the History of Health in Brazil}

\begin{abstract}
The Comprehensive Healthcare Policy for Men (PNAISH) emerges in 2009, presenting as object of attention the male social body. Given that men's health is a current theme in gender studies, we seek to recapture the main movemens of social production of masculinities crossed by medicalization in different historical conjunctures. To that end, we rely on post-structuralist conceptual operators that seek to take masculinities as product of certain contexts characterized by relations of power-knowledge and gender, as well as other social markers. Analysis points to the conditions of possibility that led certain masculinities to the field of abjection through racial marking and the labor device as a strategy
\end{abstract}

* Endereço para correspondência: Universidade Federal do Rio Grande do Sul, Instituto de Psicologia, Programa de Pós-Graduação em Psicologia Social e Institucional. Av. Ramiro Barcelos, 2600, Santana, Porto Alegre, RS, Brasil 90035-003. Fone: (51) 3308-5458. E-mail: helenpsi@yahoo.com.br e hcnardi@gmail.com Apoio: Programa de Apoio a Planos de Reestruturação e Expansão das Universidades Federais (REUNI) Coordenação de Aperfeiçoamento de Pessoal de Nível Superior (CAPES) 
of power for the medicalization of male social body. In this area, the Brazilian version of masculinities transits along the bondary line between the worker and the vagabond, a line drawn by medicalization and criminalization mechanisms that operate concurrently.

Keywords: Masculinities, male health, intersectionalities.

\section{Entre el Trabajador y el Vagabundo: La Producción de las Masculinidades en la Historia de la Salud en Brasil}

\section{Resumen}

La Política de Atención Integral a la Salud del Hombre (PNAISH) emerge en 2009, colocando como objeto de atención el cuerpo social masculino. En vista de que la salud de los hombres es una temática actual en los estudios de género, buscamos retomar los principales movimientos de producción social de masculinidades atravesados por la medicalización en distintas coyunturas históricas. Para ello, nos apoyamos en operadores conceptuales pos-estructuralistas que buscan tomar las masculinidades como frutos de determinados contextos caracterizados por relaciones de saber-poder y de género, además de otros marcadores sociales. El análisis apunta a las condiciones de posibilidad que condujeron determinadas masculinidades al campo de la abyección por medio del marcado racial y por el dispositivo del trabajo como estrategia de poder para la medicalización del cuerpo social masculino. En esta segua, la versión brasileña de las masculinidades transita por la línea limítrofe entre el trabajador y el vagabundo, línea que traza por mecanismos de medicalización y criminalización operando concomitantemente.

Palabras clave: Masculinidades, salud del hombre, interseccionalidades.

A análise da emergência da Política Nacional de Atenção Integral à Saúde do Homem (PNAISH), implantada em 2009, aqui proposta em uma perspectiva genealógica ${ }^{1}$, situa os principais movimentos para uma compreensão das masculinidades na história do campo da saúde no Brasil (Ministério da Saúde, 2009). A PNAISH foi o fio condutor que nos orientou em nossa viagem ao passado para refletir sobre o presente, lembrando que o contexto de sua implantação se relaciona com diversos tensionamentos operados pela Sociedade Brasileira de Urologia em articulação com especialistas médicos (no caso, os urologistas), gestores, formuladores de políticas públicas e farmacêuticos (Carrara, Russo, \& Faro 2009). Apesar dos indicadores de morbi-mortalidade masculina apon-

Para entender o percurso genealógico é necessário distinguir outros estudos que traçam uma análise histórica. A história para Michel Foucault (1979) era pensada como uma genealogia, ou seja, uma ontologia crítica do presente. Desta forma, a genealogia se opõe a pesquisa da "origem". tarem como principais problemas os agravos relacionados a causas externas e doenças crônicas, ocorre o esquadrinhamento do corpo social masculino pela PNAISH tomando a neoplasia de próstata como central. Essa política pública também se legitimou a partir do argumento relativo à dificuldade atribuída aos homens em acessar os serviços de saúde gerando, assim, custos advindos das internações evitáveis pela Atenção Básica em Saúde.

Além de pesquisas sobre a temática (principalmente nos estudos de Sérgio Carrara, 2005; Carrara et al., 2009), a experiência empírica de uma das autoras na Política de Atenção Integral à Saúde do Homem enquanto Consultora Unesco no ano de 2013 a 2015 revela a dispersão na materialização da PNAISH nos diversos serviços tecno-assistenciais da saúde pública, bem como de sua desconsideração com a história dos homens no campo da saúde no país. Esses aspectos deslocaram-nos a outras prospecções; da dissolução de noções abstratas de "homem" enquanto identidade única, a-histórica e essencialista para entender as masculinidades enquanto diversida- 
de no bojo da historicidade de suas interrelações, rastreando-as como múltiplas, mutantes e diferenciadas (Botton, 2007; Connell, Messerschmidt, \& Fernandes, 2013; Kimmel, 1998).

Para além da ideia de homem como todo universal ou da visão essencialista ${ }^{2}$ baseada em uma compreensão restritiva e binária do sexo, a analítica queer afirma que o gênero produz os sujeitos de forma performativa, ou seja, a designação masculino não somente descreve, mas faz os corpos em ato de forma reiterada e cotidiana a partir dos regramentos de gênero que derivam de uma matriz cisheteronormativa (Butler, 2003). Matriz essa que atribui aos corpos que se adequam à norma heterossexual e ao sexo atribuído ao nascimento mais legitimidade do para aqueles que se constroem no avesso da norma (homossexuais, bissexuais, queer, pessoas trans e travestis entre outras formas identitárias e não identitárias do espectro da não cisheterossexualidade). Esse processo de esquadrinhamento do normal e do menos normal se constitui na forma contemporânea do dispositivo histórico da sexualidade que evidencia seu objetivo: formar a todos para serem heterossexuais ou organizarem suas vidas a partir do modelo supostamente coerente, superior e "natural" (Miskolci, 2009). Isto é, ser homem ou mulher não é da ordem de uma natureza anterior aos atos performativos. Tanto o

\footnotetext{
A crítica feminista da segunda metade do século XX foi a principal delatora da concepção essencialista de sexualidade, passando à compreensão de que os sexos não definem os comportamentos sociais. Concomitantemente, a ideia de uma hierarquia das masculinidades emergiu a partir da experiência de homens homossexuais com o preconceito e a violência cometida pelos homens heterossexuais (Botton, 2007; Connell et al., 2013; Medrado \& Lyra, 2008; Seffner, 2011; Vigoya, 2007). Ao procurarem definir, nos âmbitos público e privado, seu espaço na política, na economia e nas questões relativas à sexualidade, negros, mulheres e homossexuais organizaram-se para contestar a discriminação que sofriam propondo outras mentalidades para as relações sociais, questionando a masculinidade hegemônica: branca e heterossexual. Os homens então passariam a ser questionados em seu lugar universalizado e socialmente privilegiado (Souza, 2009).
}

sexo quanto o gênero são efeitos de instituições, discursos e práticas (Butler, 2008).

Assim, as masculinidades não são entidades fixas encarnadas nos traços da personalidade, e tampouco propriedade de algum tipo de essência eterna ou biológica (Kimmel, 1998). Connell et al. (2013, p. 237) mencionam as masculinidades como "uma forma de os homens se posicionarem através de práticas discursivas", e, dessa forma, podem se diferenciar de acordo com as relações de gênero em um determinado cenário social. As masculinidades além de variarem por contexto social e histórico também são construídas simultaneamente em dois campos inter-relacionados de relações de poder - nas relações de homens com mulheres (desigualdade de gênero) e nas relações dos homens com outros homens (desigualdades também baseadas em raça, etnicidade, sexualidade, geração, etc.). Assim, dois dos elementos constitutivos na construção social de masculinidades são o sexismo e a homofobia (Kimmel, 1998).

Em meio a sistemas de opressão, imbricados uns aos outros, podemos perceber por que razão (ou razões) algumas masculinidades são marginalizadas e discriminadas, enquanto outras se beneficiam de posições de privilégio (Branco, 2008; Collins, 2000). A interseccionalidade torna-se então uma ferramenta de análise que nos ajuda a compreender como diferentes marcadores sociais têm impacto na forma como se ascende aos direitos e às oportunidades. É nos pontos de intersecção que percebemos as diferentes experiências de opressão e de privilégio. Todavia, não devemos olhar a combinação dos diferentes marcadores como uma mera soma, mas sim perceber que é a articulação dos mesmos que produz experiências substantivamente diferentes.

Diante das hierarquias produzidas tendo como base os marcadores sociais, os mecanismos que possibilitam privilégios tornam-se invisíveis para aqueles que são por eles favorecidos. "Os homens brancos de classe média, por exemplo, quando se olham no espelho se vêem como um ser humano universalmente generalizável. Eles não estão capacitados a enxergar como o gênero, a raça e a classe afetam suas experiên- 
cias” (Oliveira, 1998, p. 1). Não é o que ocorre com os negros, pobres, mulheres, gays, pessoas trans e todos os que de uma forma ou de outra vêem-se como «diferentes». Do mesmo modo, ficam invisibilizados os processos de constituição de masculinidades hegemônicas e as violências envolvidas em sua modulação de si.

Nesse contexto, a historiografia brasileira, ao exaltar os "grandes homens" (heróis desta história) julgou e desqualificou os homens que eram produtos de nosso contexto social, mas que foram transformados em culpados pelo atraso do Brasil (escravizados, miscigenados, degenerados). Matos (2001), então questionou os eventos e personagens históricos ${ }^{3}$ que foram desmemoriados para se construir uma memória preponderante no país.

Memória essa recolocada por Lilia Ferreira Lobo (2008) ao pesquisar - inspirada nos estudos de Foucault (2007) -, sobre a produção social de corpos degenerescentes no Brasil:

Existências infames: sem notoriedade, obscuras como milhões de outras que desapareceram e desaparecerão no tempo.... Porém, sua desventura, sua vilania, suas paixões alvos ou não de violência instituída, sua obstinação e sua resistência encontraram em algum momento quem as vigiasse, quem as punisse, quem lhes ouvisse os gritos de horror, as canções de lamento ou manifestações de alegria. (Lobo, 2008, p. 17)

Os homens infames no Brasil são os (ex) escravizados, os nunca incluídos ou expulsos do mercado de trabalho, tidos como vagabundos ou bandidos. Quando não mortos fisicamente, o são socialmente ${ }^{4}$. Porque se vivos e não

3 Convêm salientar que as mulheres na narrativa historiográfica, também foram silenciadas nas pluralidades das formas de viver as feminilidades, descritas sob o jugo das desigualdades de gênero. A ausência das mulheres na história como parte de uma sedimentação seletiva é objeto de reflexão da autora Michele Perrot. Para a autora, a partir das décadas de 1960-1970 emerge a reivindicação de uma história das mulheres que seja escrita por elas (Perrot, 2005).

4 O que conta como uma vida vivível, quem lamenta sua morte. Apesar de toda vida ser vulnerável, Butler (2015) convoca-nos a refletir sobre porque absorvidos pelo subemprego resta-lhes serem institucionalizados. Na prisão, no manicômio ou algum lugar que lhes esconda do âmbito público. Estes são homens, na imensa maioria, negros, pobres e jovens.

Como exemplo da nossa atualidade, o mapa da violência de 2010 indica, conforme José Waiselfisz (2012), 49.932 homicídios registrados pelo Sistema de Informações de Mortalidade (SIM) do DATASUS (Departamento de Informática do Sistema Único de Saúde do Brasil), sendo que 45.617 eram homens $(91,4 \%)$ e 4.273 mulheres $(8,6 \%)$. Estes números têm apontado o Brasil como recordista mundial em homicídios, registrando 58.559 mortes violentas só em 2014, sendo mais da metade constituída por jovens (53\%) e negros (70\%; Fórum Brasileiro de Segurança Pública [FBSP], 2015). Os homens negros, jovens e pobres também são a população mais asilada nos estabelecimentos de custódia e tratamento psiquiátrico brasileiros (Diniz, 2013) e com o maior nível de encarceramento (93\%), segundo dados do Ministério da Justiça (2014), sendo que mais da metade é composto por homens negros e com até 40 anos de idade.

Consideramos assim, que a medicalização dos corpos não passa apenas pela assistência à saúde dos sujeitos, nem tampouco apenas pelo campo da saúde, mas se insere como um dispositivo de poder transversal a outros dispositivos, como o da segurança, do trabalho. Os homens infames, ao serem prioritariamente objeto das políticas de segurança pública, também o foram, indissociavelmente, foco da medicalização em território circunscrito como bordéis, casas de jogos e botecos. Em relação ao acesso à atenção à saúde, antes da emergência do Sistema Único de Saúde (SUS), somente trabalhadores de carteira de trabalho assinada tinham garantidos certos direitos. O que nos remete ao controle da força de trabalho como o primeiro alvo de atenção

certas vidas estão altamente protegidas enquanto outras vidas não recebem um apoio imediato, não se qualificam como vidas que possuem valor. Nesse sentido, a noção de abjeto se refere "a todo tipo de corpos cujas vidas não são consideradas 'vidas' e cuja materialidade é entendida como não importante" (Prins \& Meijer, 2002, p. 161). 
do biopoder em relação ao masculino (Carrara, 2005).

Biopoder é um operador conceitual cunhado por Foucault, (1999), importante para nosso estudo, pois trata-se de um modo de governar que não se preocupa somente com o indivíduo, mas lida com uma população, que é um problema político, biológico, científico e, concomitantemente, um problema de governo. Neste sentido, a biopolítica designa a maneira pela qual o poder tende a se transformar entre o fim do século XVIII e o começo do século XIX, a fim de governar não somente os indivíduos por meio de certos conjuntos disciplinares, mas o conjunto das pessoas administradas como população. Neste sentido, "o dispositivo da medicalização é interior à biopolítica, ele age conformando modos de ser" (Ignácio \& Nardi, 2007, p. 89). Principalmente depois dos trabalhos de Michel Foucault, percebe-se que o modo como os saberes científicos constroem seus objetos não é uma operação simples, nem suas consequências sociais são sempre previsíveis. Compreender certos efeitos do dispositivo da medicalização nos modos de subjetivação ${ }^{5}$ de distintas masculinidades implica em entender a forma de $\operatorname{poder}^{6}$ do

\footnotetext{
5 A subjetividade é aqui entendida como a experiência que o sujeito faz de si na relação com um determinado jogo de verdades, ou seja, são formas de ser, estar e sentir que não se encontram dentro do sujeito como uma essência, por exemplo, ou como verdade interior da pessoa, mas que compõem os sujeitos por diversos atravessamentos, por isso a expressão - processos de subjetivação (Tavares, 2011).

6 O exercício do poder consiste, portanto, em "conduzir condutas" e em ordenar as probabilidades do outro. É menos da ordem do afrontamento entre dois adversários ou do vínculo de um em relação ao outro. O poder remete à ordem do "governo", como afirma em seus escritos tardios, referindo-se não apenas às estruturas políticas e à gestão dos Estados, mas também “. . . à maneira de dirigir a conduta dos indivíduos ou dos grupos (recobrindo não) apenas formas instituídas e legítimas de sujeição política ou econômica; mas modos de ação mais ou menos refletidos e calculados, porém todos destinados a agir sobre as possibilidades de ação dos outros indivíduos. Governar, nesse sentido, é estruturar o eventual campo de ação dos outros" (Foucault, 1995, p. 243-244, apud Carvalho,
}

governo sobre a população, o qual passa a analisar comportamentos desviantes como: a delinquência, a criminalidade e o alcoolismo.

Michel Foucault (2008), apesar de não fazer uso sistemático do termo medicalização, faz referência ao processo quando aponta para a constituição de uma sociedade na qual o indivíduo e a população são entendidos e manejados por meio da medicina e demais profissões da saúde. Para o autor, a medicina social é considerada uma estratégia de saber-poder que busca estruturar um campo de ação na sociedade que opera os mecanismos de produção de subjetividade. Portanto, diferente da tradição crítica à medicalização, a análise foucaultiana destaca seu aspecto produtivo, sua capacidade de fabricar novas verdades e técnicas para responder às mais variadas possibilidades de ação dos sujeitos na sociedade (Carvalho et al., 2015).

Diante desses conceitos centrais, revisitaremos os principais acontecimentos históricos que fomentaram o jugo moral que vitimizam-culpabilizam o corpo social masculino, dirigido principalmente aos homens negros pobres e jovens que sofrem processos de criminalização, ao propor aberturas conceituais que potencializem a inclusão do campo das masculinidades nos estudos e debates no campo das políticas públicas?

\section{Do Trabalho (e do) Escravizado: A Raça como Estratégia de Biopoder Até o Período da República Velha}

Os escravizados (as $)^{8}$ trazidos nos navios negreiros ao Brasil possuíam uma vida "útil" de 06

Rodrigues, Costa, \& Andrade, 2015).

7 O conceito de co-produção sugere que as formas de fazer política de um determinado contexto sóciohistórico estão intimamente ligadas às formas de ordenamento científico preponderantemente legítimos naquele momento, legitimidade que enraíza-se no ambiente cultural deste mesmo contexto (Marques et al., 2012).

8 A escravidão formalmente datada na história do Brasil vigorou durante 388 anos, tendo durado desde o seu descobrimento em 22 de abril de 1500 , até o final do século XIX quando esta foi mundialmente proibida. Aqui no Brasil, sua abolição se deu em 13 de maio de 1888 com a promulgação da Lei Áurea, feita pela Princesa Isabel. 
a 10 anos, expostos a acidentes de trabalho, doenças infecciosas e epidêmicas (Kodama, 2008; Pinheiro, 2002; Porto, 2008). Cláudio Pinheiro (2002) salienta o grande número de homens, em comparação às mulheres e crianças, sendo que as estimativas do número de escravizados a partir do tráfico negreiro varia entre 3, 6 milhões e 4,8 milhões (Lobo, 2008). Impedido de constituir família, abandonado nas Santas Casas quando doente e até mesmo enforcado e dilacerado em praça pública, a história da escravatura é fundamental para entendermos posteriormente neste estudo, os mecanismos de poder soberano que coexiste a outras economias do poder em nossa atualidade, especificamente às masculinidades que vivenciam as desigualdades sociais por raça e classe social.

O soberano, segundo Foucault (1999), detinha o poder de vida e morte de seus súditos, poder de fazer morrer e deixar viver. Na sociedade escravista brasileira não só os castigos corporais eram correntes, como também os espetáculos de suplício em praça pública. Ao decretar a morte dos súditos, o soberano exercia, também, o poder sobre a vida. No contexto da escravidão brasileira a monarquia portuguesa, com seu "direito penal real" delegava aos proprietários de escravos, a prática da justiça privada, fato endossado pelos textos jesuíticos que reconhecem o direito senhorial de castigar fisicamente, enquanto estratégia fundamental no exercício de poder sobre o escravo (Veiga-Neto, 2010).

$\mathrm{O}$ corpo do escravo enquanto um corpo-mercadoria não era objeto para a medicina no Brasil. Os poucos médicos do período colonial tinham como alvo principal a família dos ricos; como se a procriação de um sujeito considerado inferior fosse indesejada e o cuidado à saúde relevante apenas para sustentar a mão de obra necessária (Lobo, 2008).

Apenas a partir da abolição em 1888 e da proclamação da Primeira República no ano seguinte, que a ciência emergiu como ferramenta de autoridade cada vez mais importantes para a análise da sociedade brasileiras, "é nesse contexto que se propagam os enunciados referentes ao racismo biológico e a degeneração". Na primeira República, uma das principais preocupações dos governantes estava direcionada à transformação urbanística da capital. A missão civilizadora não se restringia ao embelezamento do espaço público e à adoção de políticas sanitárias de arejamento do centro do Rio, que resultaram na Reforma Pereira Passos, em 1903, e na Revolta da Vacina, em 1904. "Ela também implicou a necessidade de modernização de todos os aparelhos de repressão" (Menezes, 1996, p. 32). De um lado, temos então, desde o início do século XX, no contexto da República Velha, o Brasil em grande expansão econômica e notável transformação social (Carrara, 2004), na qual os homens passam a serem os braços de uma sociedade em plena expansão das fazendas de café e na industrialização. Por outro lado, homens pobres (principalmente os ex-escravizados), ocupando os mais diversos ofícios urbanos e rurais muitas vezes em condições deploráveis (Kodama, 2008; Lamounier, 2007; Lobo, 2008).

A resistência ao trabalho ou sua incapacidade/impossibilidade era vista como vagabundagem que deveria ser combatida pela lei. Chalhoub (2001) afirma que em 1889 o projeto de repressão da ociosidade, elaborado pelo ministro Ferreira Viana, foi votado quase unanimemente pela Câmara, pois uma preocupação recorrente era de que o ex escravizado liberto comprometesse a ordem e para isso deveria ser reprimido.

A lógica do soberano, oficialmente, já não cabia mais nos modos de punição do crime na república Velha, pois o foco agora é a defesa da sociedade burguesa. A vigilância policial criava, assim, mecanismos de controle dos espaços que cada masculinidade era autorizada a ocupar a partir de marcações de poder que envolviam o corpo do trabalhador livre. Os indivíduos que se encontram no botequim e nas ruas e que não conseguiam provar sua condição de trabalhadores eram punidos quando não institucionalizados $^{9}$. O projeto contra a vagabundagem era

\footnotetext{
9 “'A entrada do 'duplo ilícito', ou seja, do crime e da contravenção no Código Penal de 1890, pode ser vista como a contrapartida da elite republicana à liberdade adquirida pelos escravos no período imediatamente anterior" (Santos, 2009, p. 105, apud Silva, 2012). Segundo Marilene Sant'anna (2002) as Casas de Correção nessa época era des-
} 
voltado às masculinidades que circulavam pelo território público de maneira contrária ao prescrito. Não foi apenas o dito vagabundo; perigo social para o bem estar de uma nação que vinha a se constituir, mas outros corpos infames, como os leprosos, sifilíticos e loucos passaram pelo crivo da tática de poder da polícia.

Ressalta-se que eixo identitário "vagabundo" foi uma terminologia inspirada no termo importado de "classes perigosas". Chalhoub (2001) explana que o termo classes perigosas apareceu originalmente na Inglaterra, inspirado no Tratado da Degenerecência de Benédicte Auguste Morel datada de 1857 (Lobo, 2008). Para Morel, o termo classes perigosas era sinônimo de pobreza. "Os pobres apresentam maior tendência à ociosidade, são cheios de vícios, menos moralizados e podem facilmente rolar até o abismo do crime" (Lobo, 2008, p. 54). Os médicos brasileiros, inspirados nos postulados de Morel, reconheceram os fatores morais como associados à degenerescência e se apressaram a fixá-los na hereditariedade.

A importação dos ideários eugênicos se associava diretamente aos temores da elite brasileira. A medicina social brasileira, a partir do período republicano, respaldada na perspectiva heteronormativa e higienista ${ }^{10}$ emerge então como complementar às ciências sanitárias já existentes. A ideia "sanear é eugenizar" (Stepan, 2004) demarca os limites entre público e privado, apresentando o bar, cabaré e botequim, como territórios perigosos para a constituição de homens para a vida na cidade, em contraposição, a fábrica, a oficina e ao escritório, espaços de tra-

tinada prioritariamente aos homens criminosos, julgados e condenados. Já a colônias de tratamento eram mais destinadas aos contraventores da ordem, da moral e bons costumes (vadios, alcoolistas, cafetões, doentes mentais...). De qualquer modo, em ambas as instituições imperava a lógica do trabalho forçado, tanto como punição, como tratamento moral.

10 Ressalta-se que "a eugenia brasileira da década de 1920 não foi um movimento de higienização ao estilo nazista, disposto a esterilizar ou eliminar alguma raça. Como poderia sê-lo, se nem todos os membros da elite estavam seguros da 'pureza' de seu sangue?" (Stepan, 2004, p. 356). balho e espaço do lar eram formadores do bom homem. Considerava-se que os espaços de lazer encorajavam a indisciplina e libertinagem. Neles se misturavam sociabilidade, violência, prazer e desordem, causando problemas no trabalho e ruína doméstica. O sexo produtivo, neste sentido, era aquele que permitia garantir o povoamento $\mathrm{e}$, ao mesmo tempo, o branqueamento ${ }^{11}$, gerando indivíduos que aplicassem a sua força de trabalho de forma útil. Já o sexo improdutivo deveria ser vigiado e evitado. Costa (2007) reforça que a eugenia envolvia o combate ao alcoolismo e a sífilis dos procriadores, a proibição das uniões de indivíduos tarados e homossexuais e a segregação e esterilização dos degenerados.

A eugenia buscava a organização da sociedade e sua expansão perpassou o âmbito das diversas ciências e políticas públicas. Assim, o homem negro além de ser caso de polícia era também de psiquiatria. Conforme Matos (2001), a eugenia foi para a psiquiatria um instrumento teórico posto a serviço da crítica ao sistema democrático-liberal da República. Mas a preocupação eugênica com o povo brasileiro não ascende da psiquiatra. Foram os homens historiadores, antropólogos, sociólogos, literatos, os primeiros a difundir na cultura brasileira as ideias de eugenia, originados dos meios intelectuais europeus, no início do século XX. A psiquiatria somente

11 Em finais do século XIX, o Brasil mestiço tinha no branqueamento em um século, sua perspectiva, saída e solução. $\mathrm{O}$ desempenho importante da hereditariedade justifica as causas de numerosas doenças e desvios, em particular das doenças mentais (alcoolismo, delinquência, epilepsia, esquizofrenia, psicose maníacodepressiva, idiotia, imbecilidade; Lobo, 2008). Mais ainda, a mistura racial era vista como causa, não de degeneração, mas de regeneração, porque levava a um progressivo branqueamento da população por meios naturais. À medida que a tese do branqueamento ganhava terreno, nas décadas de 1920 e 1930, como ideologia não oficial da elite, muitos brasileiros desviavam sua atenção do pessimismo racial para a educação, a reforma social e o saneamento como respostas ao 'problema nacional'. "O resultado foi um movimento eugênico que, conquanto se fundasse em ideologia racista, foi sutilmente afastado de um racismo declarado" (Stepan, 2004, p. 359). 
reelaborou, a sua maneira, a discussão de um tema corrente nos meios intelectuais da época a partir da Liga Brasileira de Higiene Mental (LBHM).

A LBHM foi fundada no Rio de Janeiro em 1923, pelo psiquiatra Gustavo Riedel, com a ajuda de filantropos de seu círculo de relações. De acordo com Costa (2007), o objetivo inicial da instituição era o de melhorar a assistência aos doentes mentais através da renovação dos quadros profissionais e dos estabelecimentos psiquiátricos. Todavia, Lobo (2008) afirma que a partir de 1926, os psiquiatras começaram a elaborar projetos para a prevenção, eugenia e a educação dos indivíduos para que estes não se tornassem doentes. A ação terapêutica deveria exercer-se no período pré-patogênico, antes do aparecimento dos sinais clínicos.

A LBHM passou então, a ter clara intenção de reformar a sociedade, impondo-lhe normas de comportamento, medidas proibitivas de casamentos e procriação como dispositivos de aperfeiçoamento da raça, entendida inicialmente como sinônimo de espécie humana (Lobo, 2008). Desse modo, os médicos constituirão em sua prática, o corpo doente como corpo racializado, tendo como finalidade a construção de uma biotipologia brasileira saudável, forte e laboralmente produtiva. Se na cena pública a literatura eugênica utilizava a palavra 'raça' invariavelmente, no singular, para referir-se ao 'povo brasileiro', na esfera privada ela significava a 'raça negra'. A partir desses ideários a eugenia brasileira se solidifica associada à mobilização pela introdução de políticas sociais como forma de aprimorar o povo brasileiro.

\section{Do Operário ao Vagabundo: Saúde e Trabalho no Brasil a Partir do Período Estado Novo}

No século XIX, um dos clássicos debates ocorridos no mundo ocidental foi sobre a "verdadeira" origem da riqueza de uma nação; discussão que no Brasil se fez presente no período Imperial desafiou a Primeira República e se inverteu a partir da Era Vargas. Até a República Velha, Vanessa Xavier (2010), salienta que o que se tinha era um Estado, mas não a Nação.
Para se ter a Nação, seria preciso que o povo tivesse características uniformes, que dessem uma identidade ao brasileiro e permitissem seu reconhecimento. E foi essa a estratégia fundamental de Getúlio Vargas no período do Estado Novo (1937-1945).

Vimos que, na medicina social do período anterior, o objetivo central era prevenir as possíveis causas de degenerescências do homem produtivo. Tinha-se, então, como objeto de preocupação da medicina, a degeneração. Diferentemente, no período do Estado Novo, a principal estratégia de poder, será o enaltecimento do homem trabalhador, ressaltando sua dedicação para o labor, independente de hierarquia profissional.

A pobreza, neste governo, seria suprimida pelo trabalho e pela legislação social, buscando-se humanizar e dignificar as condições de vida. O homem trabalhador é elevado como sujeito merecedor de algumas garantias e por isso a legislação vem, então, ampará-lo, bem como a sua família. Ao mesmo tempo, disciplina o trabalho, dissipando as greves e propondo o Estado como mediador da luta de classes. Proteção legal que vinha associada a um discurso de valorização do trabalho manual, do trabalho árduo, da dedicação expressiva, do senso de honestidade e honra, em contraposição ao estigma da pobreza.

Neste processo de 'melhoramento' do homem brasileiro, as Forças Armadas, principalmente o Exército é visto como eixo central. Maurício Parada (2006) situa que além dos militares, crescia entre os médicos higienistas e pedagogos, uma preocupação com a prática desportiva. Esses especialistas vão produzir uma interpretação fundamentalmente moral sobre o tema: o aprimoramento físico deveria estar relacionado a ideais muito mais elevados como a melhoria do tipo racial e a intensificação do sentimento cívico. A juventude tornou-se foco da disciplinarização das masculinidades, para que fossem criados "os bons homens" que seriam os trabalhadores, pais de família.

A fim de garantir a proteção social prometida a esses, a organização política engendrada no governo Vargas, se organizou em dois Ministérios, criados ainda ao final de 1930: O Ministério da Educação e Saúde Pública e o Ministério do 
Trabalho, Indústria e Comércio (Ponte \& Reis, 2010). Neste último, estabeleceu-se o arcabouço jurídico e material da assistência médica individual previdenciária, que, com o passar dos anos, se tornaria uma das principais referências para a prestação de serviços públicos de saúde. Ressalta-se também, a constituição de 1934, que incorporou algumas garantias ao operariado, tais como assistência médica, a licença remunerada à gestante trabalhadora e a jornada de trabalho de oito horas. Nos anos subsequentes, outros benefícios, como o salário mínimo, foram incluídos na legislação trabalhista, culminando com o estabelecimento em 1943 da Consolidação das leis do Trabalho (CLT). Pela CLT, tornavam-se definitivamente obrigatórios o pagamento do salário mínimo, a indenização aos acidentados, o tratamento médico aos doentes, o pagamento de horas extras e as férias remuneradas a todos os trabalhadores portadores de carteira de trabalho. Ponte e Reis, (2010) também revela que o modelo oferecido pela lei Eloy Chaves foi parcialmente adotado por Getúlio Vargas, na década de 1930, em várias categorias profissionais. Organizaram-se então as caixas de aposentadorias e pensões e os institutos de previdência. Sob a tutela do Estado, esses órgãos garantiram assistência médica a uma vasta parcela da população urbana sem gastar nenhum recurso financeiro da administração federal.

Ainda assim, conforme Cláudio Bertolli (2008), as caixas apresentavam serviços irregulares, oferecendo pouca cobertura aos doentes mais graves. Carlos Ponte e Reis (2010) salienta a desmobilização do poder sindical, visto que cada sindicato dividido por categorias profissionais eram estimulados a buscar individualmente o cumprimento da legislação no Ministério do Trabalho, Indústria e Comércio, na intenção de buscar a efetivação do direito ao segurado.

Ademais, a dedicação ao bem-estar dos homens, circunscrevia-se apenas aos trabalhadores assalariados, estes, desfrutavam da ampliação de acesso às garantias trabalhistas. Trabalhadores autônomos, desempregados e outros corpos sociais, incluindo o trabalhador rural (Ponte \& Reis, 2010), estavam excluídos deste contingente populacional; aos desprovidos, restava apenas a caridade dos hospitais filantrópicos para eventuais atendimentos de saúde.

E para aqueles que questionavam o governo ou restringiam a norma, como alguns escritores, artistas da época, os comunistas, anarquistas, homossexuais e aos negros (que mantinham os costumes e religiões de matriz africana), o Estado Novo buscou a desmobilização da vida coletiva pela censura e punição. Vale salientar, que o crescimento da medicina legal neste período, contribuiria para um aumento do racismo, uma vez que com frequência nas caracterizações do criminoso, o negro era escolhido como o biótipo preferencial. Nota-se que o racismo ainda justificava a degenerescência desses homens, mesmo ao enaltecer inclusão da heterogeneidade das diferentes raças na composição da identidade nacional.

Todas essas estratégias de poder do Estado Novo foram reinvestidas no contexto da ditadura civil-militar $^{12}$ (1964-1985), de caráter nacionalista, desenvolvimentista e de oposição ao comunismo. A ditadura atingiu o auge de sua popularidade na década de 1970, com o «milagre econômico», no mesmo momento em que o regime censurava todos os meios de comunicação do país e torturava e exilava dissidentes (Bertolli, 2008; Ponte \& Reis, 2010). Essa configuração político-econômica movimentou o êxodo rural brasileiro, entre 1960 e 1980, com cerca de 27 milhões de pessoas. Mas, aos trabalhadores rurais, restou esperar até 1971 para que tivessem garantidos seus direitos previdenciários (Bertolli, 2008).

Desvios de verbas do Ministério da Saúde/ Instituto Nacional de Previdência Social (INPS), terceirização dos serviços para os hospitais pri-

12 Em 31 de março de 1964, militares contrários ao governo de João Goulart (PTB) destituíram o então presidente e assumiram o poder por meio de um golpe. O governo comandado pelas Forças Armadas durou 21 anos e implantou um regime ditatorial. O Golpe também recebeu forte apoio da camada civil da sociedade brasileira, chegando a ser financiado e embasado por grandes empresas, meios de comunicações e personalidades influentes na sociedade da época. Por isso, nesse artigo será usado e problematizado o termo Ditadura Civil-Militar (Ribeiro, 2016). 
vados, achatamento salarial, desinvestimento da prevenção em prol do curativismo, são alguns dos principais marcadores político-econômicos do período. Além disso, os indicadores de mortalidade infantil eram alarmantes, contrastando com a alta incidência de morte de homens por acidente de trabalho (Bertolli, 2008; Ponte \& Reis, 2010).

O trabalho na indústria nos anos 1970 foi considerado como uma possibilidade de adquirir uma profissão socialmente valorizada e que permitia a ascensão social (Bertolli, 2008; Ponte \& Reis, 2010) e em 1974 foi criado o Ministério da Previdência e Assistência Social. Entretanto, Carlos Bertolli (2008), conta-nos que nesta época, o INPS ameaçava sucumbir face à incapacidade gerencial e à complexidade do sistema previdenciário, além da enxurrada de fraudes dos hospitais privados.

Enquanto isso, cerca de um quarto dos dois milhões de trabalhadores da construção civil foram vitimados por acidentes de trabalho. Diante da violação de direitos, temos ao final dos anos 1970, o movimento sindical, em sua potência de resistência às agruras do labor do operariado (Bertolli, 2008). As greves dos metalúrgicos do ABC paulista, conforme Nardi (2006) marcam o nascimento do novo sindicalismo. As temáticas da reforma do Estado e da seguridade social, como afirma Sonia Fleury (2009), estiveram ausentes da agenda e do discurso das esquerdas no Brasil até os anos setenta, até que as greves do $\mathrm{ABC}$ rompessem com o silêncio imposto aos movimentos sociais durante a ditadura civil-militar.

Mesmo na invisibilidade de problematizações sobre os homens na história, foi justamente o movimento sindical de trabalhadores que produziu as discussões propiciadoras na VIII Conferência Nacional de Saúde e a realização da I Conferência Nacional de Saúde dos Trabalhadores. Ambas foram decisivas para a mudança de enfoque estabelecida na nova Constituição Federal de 1988 (Mendes \& Dias, 1991). Assim, a Constituição de 1988 tentou estabelecer um corpo de princípios que universalizaria às proteções próprias à sociedade salarial e ao Estado Social, a partir do modelo de proteção social que irá agregar e assegurar os direitos relativos à saúde, previdência e assistência social. Entretanto, não se considerou o não assalariamento de mais de $50 \%$ da população à época. Ademais, o modelo de 1988 foi confrontado pelas políticas econômicas neoliberais que se sucederam a partir de 1989 (Nardi, 2006). Apesar do Sistema Único de Saúde ser garantido a partir da constituição de 1988 , ao longo da década de 90, o funcionamento das instituições públicas se afinam com a desigualdade social; há uma segmentação das clientelas entre a assistência pública (para os pobres) e a privada, esta última formalizada pela regulamentação da assistência supletiva no final da década de 1990, o que evidencia a inviabilidade do ideal de saúde como um direito de todos e dever do estado (Souza, 2011).

Não podemos negar, no entanto, que vemos a tentativa de se criar um Estado Social que nunca se efetivou de fato. Como forma análoga à propriedade salarial, temos o sistema de proteção ligado à carteira assinada que foi denominado cidadania regulada ${ }^{13}$ e a já citada tentativa de universalização dos direitos sociais afirmados na constituição de 1988 (Brandão, 2002).

Temos então diante de processos de subjetivação atuais, o trabalhador ideal envolvido em outras facetas pelo contexto neoliberal. A família, por exemplo, continua central, mas agora do ponto de vista de assegurar a sobrevivência dos seus, mesmo que em detrimento dos outros, desconstituindo a noção de coletividade presente na identidade do operário padrão. Conforme Nardi (2006), a ética do provedor continua presente, mas amputada dos valores relativos ao companheirismo e à justiça.

\footnotetext{
13 A questão para Santos (1987), portanto, não são os valores e as normas internalizadas que permitem o (não) reconhecimento do status de igualdade substancial entre os indivíduos de uma comunidade política para a formação da Cidadania, mas o traço da cidadania regulada que se desenvolve no Brasil estaria intimamente relacionado com a ocupação do indivíduo, ocupação essa que deveria ser reconhecida e definida pela lei. Nesse sentido, a extensão da cidadania estaria fundamentada na regulamentação das profissões e ocupações mais do que nos valores e no reconhecimento do indivíduo enquanto membro de uma comunidade (Santos, 1979, apud Teixeira, 2014).
} 
De uma situação de salários fixos, contratos de duração indeterminada com possibilidades de progressão funcional e negociação coletiva; chegamos hoje a uma infinidade de novas relações de trabalho, tais como: contratos flexíveis, temporários, com variações de remuneração e trabalho no domicílio, negociação individual, alternância de períodos de desemprego e trabalhos temporários, subcontratação e terceirização. O movimento sindical também se fragiliza nessa nova configuração e se encontra desorientado no enfrentamento dos argumentos de cooptação presentes nas novas formas de gestão. (Nardi, 2006, pp. 58-59)

Castel (1998) vai problematizar o neoliberalismo, entendendo que ele reconstrói as condições para que os homens e, mais tarde, as mulheres, tornem-se proprietários de si mesmos. Propriedade social é um conceito-chave para o desenvolvimento da sociedade democrática ocidental moderna e é definida enquanto um tipo de propriedade que não se pode comprar no mercado e que depende de um sistema de direitos e obrigações. A nova configuração do trabalho fez emergir os homens desfiliados, (Brandão, 2002; Castel, 1998) que corresponderiam então, aos 'inúteis para o mundo' ou os "supranuméricos". O "supranumérico" não consegue sequer ser explorado no mercado de trabalho; é um indivíduo "supérfluo" que não possui um lugar demarcado na sociedade exatamente porque não carrega competências que sejam úteis para o conjunto desta. Das vidas que merecem ser vividas, o homem considerado vagabundo, nem mesmo é contabilizado na população.

Como supranumerários no Brasil incluímos trabalhadores do setor informal, os quais, somente após a criação do SUS passam a ter direito a ser atendidos no sistema público. Gomez e Lacaz (2005); assim como Mendes e Campos (2004), afirmam que não existem informações disponíveis sobre os índices de acidentes do trabalho e de doenças profissionais e relacionadas ao trabalho informal. $\mathrm{Na}$ atualidade, o sistema de saúde representaria a única alternativa disponível, de curto prazo, para assegurar, aos trabalhadores do setor informal uma atenção à saú- de diferenciada, que contemple sua inserção no trabalho, uma vez que estes trabalhadores estão descobertos do amparo legal no que se refere à previdência social. Dentro da seguridade social, estes trabalhadores seriam acolhidos pela assistência social e pelo SUS.

Se na história do Brasil, a produção social de masculinidades legitimadas era atrelada à categoria de trabalhador, questionamos como dentre os arranjos de masculinidades é produzido este modelo e seu oposto. Segundo Nardi (2003), esse processo se deu por meio do conjunto de regras morais que constituem a prática do trabalho, que agiu como dispositivo ${ }^{14}$ central da integração social e, ao mesmo tempo, como uma forma de acesso à proteção do Estado.

Contrário ao estigma é justamente pelo temor de estar improdutivo ou incapacitado que os homens negam o adoecimento (Tittoni, 1994). O resultado disso é o agravamento da doença e a dificuldade de programar estratégias preventivas no universo do trabalho. Conforme Bendassolli, (2000), com enraizamentos sociais e subjetivos importantes, tem-se a equação: corpo inválido = indivíduo sem trabalho = indivíduo inválido. Similarmente Nardi (1998) complementa o caráter moral, designado ao trabalhador que adoece: trabalho $=$ saúde $=$ honestidade, versus doença $=$ vagabundagem. Ao invés de se modificar o modo como o trabalho é organizado e executado, se culpa o trabalhador que se acidenta ou adoece pelo próprio infortúnio.

Como exemplo, temos o estudo de Nardi, (1998) que, ao percorrer o caminho dos trabalhadores que foram encaminhados para perícia do Instituto Nacional do Seguro Social (INSS), vemos a doença atribuída como "simulação", o sujeito vagabundo novamente dá as caras. $\mathrm{O}$ médico perito produz suas estratégias de defesa contra uma demanda infindável para os benefícios disponíveis a serem liberados. Não é raro

\footnotetext{
14 “. . . é isso o dispositivo: estratégias de relações de força sustentando tipos de saber e sendo sustentadas por eles. Para dizer: 'eis um dispositivo', procuro quais foram os elementos que interviram em uma racionalidade, em uma organização" (Foucault, 2007, p. 124).
} 
então, que se assuma uma postura de total inércia com o sofrimento do sujeito, desprendido do processo coletivo que envolve a análise do ambiente e organização do trabalho.

Novamente, ao homem, resta-lhe mostrar uma faceta frágil e incapaz de se sustentar como trabalhador para que possa ser objeto de atenção. Revestido como sujeito a partir do maniqueísmo moral, o trabalhador que busca a atenção à saúde, já não o é mais, pois é revertido em "vagabundo". O vagabundo, mostrando que seu sofrimento de fato não é simulação, consegue ancorar aos olhos da medicina social sua incapacidade. Transmutado em vítima de suas próprias incapacidades, este homem nada mais é do que uma masculinidade na linha limítrofe das masculinidades ilegítimas.

A PNAISH concebe como norma um homem que, assim como a mulher adere aos preceitos da medicalização. Contudo, esta construção social emperra numa aparente contradição: constatamos que os homens no contexto brasileiro, a partir do momento que se afastam de suas incumbências laborais pelo adoecimento já ferem o imperativo do ser homem. Porque homem que é homem não adoece. Diria a empresa, o colega da cela e até mesmo o próprio homem adoecido, pois assim fora "criado". Ou seja, o homem que tem que ter uma saúde de ferro, foi submetido pela PNAISH ao regime discursivo que o impele a reconhecer sua fragilidade, ao passo que as masculinidades são móveis e tensas.

Num contexto político e social em que não há garantias empregatícias e de extrema competição, o trabalhador de hoje pode ser o "vagabundo de amanhã". O campo da saúde é o lócus onde os homens serão lembrados disso, como bem vimos, quando estes buscam ser acolhidos em seu sofrimento, desde a procura por consulta médica, até mesmo quando é decidida a concessão de seu benefício. Ficar doente é atestar que se está circulando fora da norma.

\section{Trabalho e Outras Institucionalizações: O Destino de Masculinidades Racializadas}

$\mathrm{Na}$ seção anterior buscamos refletir sobre a frágil representação do bom homem enquan- to trabalhador ao situar historicamente políticas públicas que, ao invés de proporcionar o mínimo de acesso a direitos sociais, incluindo a saúde, enlaçam os homens numa rede de precariedade, adoecimento e exclusão. Resta-nos desse modo complementar em nossas problematizações finais, a dimensão da performatividade de masculinidades racializadas, diante de uma sociedade que preconiza um estado penal que se espraia nas políticas sociais. Ser vagabundo não é apenas não cumprir seus deveres como corpo útil à sociedade; há aí uma dimensão de raça. Ao serem submetidos a condições de trabalho insalubres e de risco, ou no mercado informal, homens negros e pobres ocupam o quase inquebrável estatuto de vagabundos e criminosos.

Começamos nesse estudo nossa análise pelo homem escravizado, enquanto corpo social masculino que situa a linha condutora das masculinidades produzidas por meio da noção de raça, enquanto tática de poder no interior do dispositivo da medicalização. Dos tempos coloniais, passando pela eugenização da Liga Brasileira de Higiene Mental no período da República Velha, a noção de raça amplia as formas disciplinares sobre os corpos. A raça, enquanto próprio inventário do racismo introduzirá o homem branco como norma pelo discurso de poder-saber da medicina (Foucault, 1999).

A teoria da degenerescência frutificou $o$ terreno de disciplinamento dos corpos e como estratégia, tinha não mais a morte física dos infames, mas a prisão como parte operante da produção de subjetividade, que confere aos homens seu estatuto de criminoso. Vemos desta maneira, que graças à medicina social, o vagabundo adquiriu seu pleno status de periculosidade, instaurando desta forma, um problema social que o encarceramento poderia resolver. $\mathrm{O}$ perigo social brasileiro vai localizar-se no comportamento da população não branca. Salienta-se que o termo perigoso é utilizado por Foucault (2008) como analisador da sociedade caracterizada pelo poder disciplinar, enquanto condição de possibilidade da emergência da norma, que é o próprio fundamento relacional da disciplina. O perigo, portanto, habita o sentido do incontrolável, do imprevisível, "das virtualidades". 
Assim, a emergência da medicina social aos corpos potencialmente perigosos disseminou-se pelo tecido social, introduzindo aos poucos sua ação normalizadora, não apenas na prisão, mas a partir do hospital (sua primeira tomada de poder), nas famílias, nas escolas, "nos quartéis, nas fábricas, até penetrar sua nova racionalidade no aparelho do Estado: o controle e a organização das condições de vida dos indivíduos e das populações, incluído a disciplinarização dos trabalhadores livres" (Lobo, 2008, p. 10).

Nesse sentido, o autor Loic Wacquant (2003) contribui ao descrever em seus estudos a mão invisível do mercado de trabalho às populações pobres, encontrando seu prolongamento ideológico e seu complemento institucional no estado penal, que se amplia e se desdobra de modo a controlar as desordens geradas pela difusão da insegurança social e pela desestabilização correlata das hierarquias estatutárias que configuravam a armadura tradicional da sociedade nacional. Políticas sociais (entre elas a saúde) e políticas penais costumam ser abordadas separadamente, tanto pelas ciências sociais como pelas políticas públicas. Entretanto Loic Wacquant (2008, 2013) afirma que não podemos separar corpo, Estado social e penal e a marginalidade urbana: é necessário captá-los e explicá-los em conjunto, nas suas imbricações mútuas.

Assim, quando é inferido que o espaço público é dos homens, percebemos que é necessário por em questão que para masculinidades rejeitadas em sua circulação resta-lhes o território privado das instituições. Autores na área de estudos sobre masculinidades como Michel Kimmel (1998), Welzer-Lang (2001, 2004), Pedro Oliveira (1998) já nos haviam situado que o processo de higienização do corpo social masculino ocorre em "lugares onde os homens aprendem a ser homens". A partir desta argumentação, descrevem os lugares monossexuados destinados aos meninos quando estes saem da custódia das mulheres para se tornarem, por assim dizer, "homens de verdade". Este processo de ser reconhecido como homem passa pelo território do Estado, visto que a prisão, o manicômio, e escola são instituições aonde as masculinidades vão sendo reiteradas, a partir da diferenciação do oposto a tudo que é tomado como feminino, passando por provas de hombridade dos mais velhos com os mais novos, ou os hierarquicamente superiores. Este percurso do tornar-se homem é muitas vezes carregado de violência e, de acordo com a história que percorremos, podemos inferir que a violência de Estado faz parte desse processo genereficador. Welzer-Lang (2004), complementa que os homens (principalmente os negros e pobres) ao não serem associados a nenhum símbolo de riqueza, de reconhecimento social, "investem no lugar simbólico (da hegemonia masculina) que lhes é possível" (Oliveira, 2004, p. 285).

Suas performances então passam a ser justamente incentivadas pelo processo de subjetivação que posiciona as masculinidades racializadas com atributos de força, virilidade, vigor e destreza física, uma suposta animalidade. Estes valores estão na base da constituição do colonialismo e do escravismo, que também os colocam como intelectualmente e emocionalmente incapazes. Os homens negros são obstruídos na realização de uma masculinidade nos termos dos homens brancos, ao mesmo tempo em que não lhes é permitido reconstruí-la de acordo com os atributos masculinos das sociedades africanas (Ribeiro, 2016).

Complementarmente, autores, como Jessé Souza (2011), explicita as dimensões de classe social relativo às nuances das masculinidades nas comunidades periféricas, ao perceber a eterna tensão entre ser um trabalhador honesto, com valores impostos socialmente, ou ser um homem de vida fácil, bandido. No capítulo - $O$ crente $e$ o delinquente e - o trabalho que (in) dignifica o homem" encontramos um material empírico que acompanha a vida dos homens destituídos de reconhecimento social. Há aqueles que dizem ter a saúde (integridade do corpo) como o maior bem que possuem, justamente por não se envolver em conflitos violentos e na ilegalidade. Quando a religião insere-se na vida destes homens ela é a esperança de um futuro melhor, se não neste mundo injusto, numa existência posterior, onde serão recompensados de algum modo por agirem corretamente (que seria não ser violento, ser responsável, provedor). 
Acontece que vestir a camisa do homem bom trabalhador é quase impossível. Vejamos: ao ser um menino ou jovem da ralé (termo resgatado por Jessé Souza) é necessário acompanhar a linguagem, o método de ensino, esquecer os problemas de casa, pois o fracasso escolar é uma marca de incapacidade que poderá ser anulada pela via da delinquência, talvez a única possibilidade de construir uma identidade positiva mesmo que apenas nos limites estreitos de seu contexto de vida (Ribeiro, 2016; Souza, 2011).

A escola, nesse contexto, permite ascensão social pelo estudo para todos. Mas o que ela faz na prática institucional é separar as classes nascidas para vencer das classes nascidas para perder. Assim, a pobreza do Estado Social sobre o fundo da desregulação suscita e necessita da grandeza do Estado Penal. E isso é mais forte quanto mais o Estado se livra de qualquer responsabilidade social e tolera, ao mesmo tempo, um elevado nível de pobreza e uma pronunciada ampliação da escala de desigualdades. $\mathrm{O}$ acesso a políticas sociais, inclusive a saúde, como bem vimos em nossa retomada histórica, são, assim, animados por uma mesma filosofia punitiva e paternalista que enfatiza a responsabilidade individual em contraposição aos direitos e obrigações do cidadão.

Certas estratégias de medicalização tornam-se então indissociáveis do estado penal como centro de gestão da população. Vagabundos, degenerados, drogaditos, doentes, perversos. Veremos que a história parece girar em torno de uma mesma lógica punitiva de dupla regulação social: o entrelaçamento terapêutico-punitivo ${ }^{15}$, social-penal, que se desenvolve no campo problemático instaurado entre as políticas de segurança pública e saúde.

15 A metáfora remete aos "Tratamentos médicos e correcionais", utilizados desde o século XX no Brasil; é terminologia utilizada a fim de dissociar o tratamento médico do tratamento penal, o doente do criminoso. Apesar do esforço discursivo para construir um limite entre esses dois campos, na prática o que se percebe é que suas fronteiras permanecem muito mal estabelecidas (Silva, 2013).

\section{Considerações Finais}

Os estudos iniciais sobre a PNAISH nos conduziram à análise do presente, seguindo as continuidades e rupturas nos contextos históricos que movimentaram determinadas produções de masculinidades em diversas territorialidades, tanto aquelas consideradas legítimas perante a sociedade como corpos que serão considerados ilegítimos. O racismo científico esquadrinhou os sujeitos saudáveis e perigosos (vagabundos, desviantes sexuais, criminosos), bem como definiu a doença pela herança hereditária. Historicamente, o dispositivo do trabalho também se configura como estratégia de poder fundamental para disciplinar o corpo social masculino e torná-lo coerente às propostas biopolíticas do Estado e, pela via da normalização, se dividiram as masculinidades que transitam pela linha limítrofe entre o trabalhador e o vagabundo. Nesta seara, veremos que há um continuum punição-tratamento operando na história de certos homens, ao revelar que a medicalização e a criminalização são duas estratégias fundamentais na construção de masculinidades num contexto em que raça e classe social produzem desigualdades sociais. Se nos remetermos à Política Nacional de Atenção integral à Saúde do Homem, onde estão estes homens? As interseccionalidades de raça e classe não são discutidas nas produções do masculino, ao passo que a alta mortalidade masculina entre os jovens revela em parte a discriminação à brasileira. Ou seja, uma conduta que legitima a cor e a classe social como critérios que tornam a pessoa, um perigo em potencial.

Diante disso, além de ética e politicamente necessário para pensar nossa atualidade, consideramos fundamental a formulação de pesquisas acerca das correspondências entre o campo de saúde e da segurança pública nos serviços de emergência em saúde, com foco nas masculinidades; visto que a violência urbana emerge nestes serviços de saúde, o que pode nos oferecer novos prismas sobre produção de vida e de morte no interior das políticas públicas de saúde, uma vez que as formas de violência também estão relacionadas à violência do Estado. 


\section{Referências}

Bendassolli, P. (2000, nov.). Público, privado e o indivíduo no novo capitalismo. Tempo Social, $12(2)$.

Bertolli, C., Filho. (2008). História da Saúde Pública no Brasil. São Paulo, SP: Ática.

Botton, F. B. (2007). As masculinidades em questão: Uma perspectiva de construção teórica. Revista Vernáculo, 1(19-20).

Branco, P. (2008). Do género à interseccionalidade: Considerações sobre mulheres, hoje e em contexto europeu. Julgar, 4, 103-117. Recuperado em http://julgar.pt/wp-content/uploads/2016/05/06-Patr\%C3\%ADcia-Branco-G\%C3\%A9nero.pdf

Brandão, A. (2002). Os novos contornos da pobreza urbana: Espaços sociais periféricos na Região Metropolitana do Rio de Janeiro (Tese de doutorado, Universidade do Estado do Rio de Janeiro, RJ, Brasil).

Butler, J. (2003). O parentesco é sempre tido como heterossexual? Cadernos Pagu, 21. doi: http://dx.doi.org/10.1590/S010483332003000200010

Butler, J. (2008). Problemas de gênero: Feminismo e subversão da identidade. Rio de Janeiro, RJ: Civilização Brasileira.

Butler, J. (2015). Quadros de guerra: Quando a vida é passivel de luto? (S. T. de N. Lamarão \& A. M. da Cunha, Trads.). Rio de Janeiro, RJ: Civilização Brasileira.

Carrara, S. (2004). Estratégias Anticoloniais: Sífilis, raça e identidade nacional no Brasil do entre-guerras. In G. Hochman \& D. Armus (Eds.), Cuidar, controlar, curar - Ensaios históricos sobre a saúde e doença na América Latina e Caribe: História e Saúde (pp. 427-455). Rio de Janeiro, RJ: Editora Fundação Oswaldo Cruz.

Carrara, S. (2005, mar.). Comentários diagonais sobre a emergência dos homens na pauta da Saúde Coletiva. Ciência e Saúde Coletiva 10(1). Recuperado em http://www.scielosp.org/scielo. php?script=sci_arttext\&pid=S14138123200500 $0100007 \& \operatorname{lng}=$ en\&nrm $=$ iso

Carrara, S., Russo, A., \& Faro, L. (2009). A política de atenção à saúde do homem no Brasil: Os paradoxos da medicalização do corpo masculino. Physis Revista de Saúde Coletiva, 19(3). Recuperado em http://www.scielo.br/scielo. php?script $=$ sci arttext\&pid $=$ S01037331200900 0300006\&lng $=$ en\&nrm $=$ iso

Carvalho, S. R., Rodrigues, C. de O., Costa, F. D. da, \& Andrade, H. S. (2015). Medicalização: Uma crítica (im)pertinente? Introdução. Physis: Revista de Saúde Coletiva, 25(4), 12511269. doi: https://dx.doi.org/10.1590/S010373312015000400011

Castel, R. (1998). As metamorfoses da questão social. Petrópolis, RJ: Vozes.

Chalhoub, S. (2001). Trabalho, lar e botequim: $O$ cotidiano dos trabalhadores na Belle Epoque. Campinas, SP: Editora da Universidade Estadual de Campinas.

Collins, P. H. (2000). Black feminist thought: Knowledge, consciousness and the politics of empowerment. Nova York: Routledge.

Connell, R. W., Messerschmidt, J. W., \& Fernandes, F. B. M. (2013). Masculinidade hegemônica: Repensando o conceito. Estudos Feministas, 241-282. doi: http://dx.doi.org/10.1590/S0104$-026 \mathrm{X} 2013000100014$

Costa, J. (2007). História da psiquiatria no Brasil: Um recorte ideológico. Rio de Janeiro, RJ: Garamound.

Diniz, D. (2013). A custódia e o tratamento psiquiátrico no Brasil: Censo 2011. Brasília, DF: Editora da Universidade de Brasília.

Fleury, S. (2009). Reforma Sanitária Brasileira: Dilemas entre o instituinte e o instituído. Ciência \& Saúde Coletiva, 14(3), 743-751.

Fórum Brasileiro de Segurança Pública. (2015). $9^{a}$ Anuário Estatístico da Segurança Pública. São Paulo, SP: Autor. Recuperado em http://www. forumseguranca.org.br/publicacoes/9o-anuario-brasileiro-de-seguranca-publica/

Foucault, M. (1979). Nietzsche, a genealogia e a história. In Microfísica do poder. Rio de Janeiro, RJ: Graal.

Foucault, M. (1995). O sujeito e o poder. In H. Dreyfus \& P. Rabinow (Eds.), Michel Foucault: Uma trajetória filosófica para além do estruturalismo e da hermenêutica (pp. 231-249). Rio de Janeiro, RJ: Forense Universitária.

Foucault, M. (1999). Vigiar e Punir: Nascimento da prisão (20. ed.). Petrópolis, RJ: Vozes.

Foucault, M. (2007). Microfisica do Poder (3. ed.). Rio de janeiro, RJ: Graal. 
Foucault, M. (2008). Segurança, Território, População. São Paulo, SP: Martins Fontes.

Gomez, M., \& Lacaz, F. A. C. (2005, out.). Saúde do trabalhador: Novas-velhas questões. Ciência \& Saúde Coletiva, 10(4), 797-807. doi: http:// dx.doi.org/10.1590/S1413-81232005000400002

Ignácio, V., \& Nardi, H. (2007). A medicalização como estratégia biopolítica: Um estudo sobre o consumo de psicofármacos. Psicologia e Sociedade, 19(3), 88-95.

Kimmel, M. S. (1998). A produção simultânea de masculinidades hegemônicas e subalternas. $\mathrm{Ho}$ rizontes Antropológicos, 9, 103-117. doi: http:// dx.doi.org/10.1590/S0104-71831998000200007

Kodama, K. (2008). Os debates pelo fim do tráfico no periódico $O$ Philantropo (1849-1852) e a formação do povo: Doenças, raça e escravidão. Revista. Brasileira de História (São Paulo), 28(56). doi: http://dx.doi.org/10.1590/S010201882008000200007

Lamounier, M. (2007). Agricultura e mercado de trabalho: Trabalhadores brasileiros livres nas fazendas de café e na construção de ferrovias em São Paulo,1850-1890. Estudos Econômicos (São Paulo), 37(2), 353-372. doi: http://dx.doi. org/10.1590/S0101-41612007000200005

Lobo, L. F. (2008). Os infames da história: Pobres, escravos e deficientes no Brasil. Rio de Janeiro, RJ: Lamparina.

Marques, I. da C., Barcellos, V. A., Arellano Hernández, A., Braman, S., Cocco, G., Pádua, J. A., \& Gualtieri, R. C. E. (2012). Sheila Jasanoff: Localizando o global. História, Ciências, Saúde-Manguinhos, 19(3), 993-1040. doi: https:// dx.doi.org/10.1590/S0104-59702012000300012

Matos, M. (2001). Meu lar é o botequim: Alcoolismo e masculinidade (2. ed.). São Paulo, SP: Companhia Editora Nacional.

Medrado, B., \& Lyra, J. (2008, December). Por uma matriz feminista de gênero para os estudos sobre homens e masculinidades. Revista Estudos Feministas, 16(3), 809-840. Recuperado em http:// www.scielo.br/scielo.php?script $=$ sci_arttext\&p $\mathrm{id}=\mathrm{S} 0104026 \mathrm{X} 2008000300005 \& \operatorname{lng}=\mathrm{en} \& \mathrm{nrm}=$ iso

Mendes, R., \& Campos, A. C. C. (2004). Saúde e Segurança no Trabalho Informal: Desafios e Oportunidades para a Indústria Brasileira. Revista Brasileira de Medicina do Trabalho, 2(3),
209-223.

Mendes, R., \& Dias, C. (1991). Da Medicina do Trabalho à saúde do trabalhador. Revista de Saúde Pública, 25(5), 3-11. doi: http://dx.doi. org/10.1590/S0034-89101991000500003

Menezes, L. M. (1996). Os indesejáveis: Desclassificados da modernidade. Protesto, crime e expulsão na Capital Federal (1890-1930). Rio de Janeiro, RJ: Editora da Universidade do Estado do Rio de Janeiro.

Ministério da Justiça. (2014). Execução penal. Sistema Integrado de Informações Penitenciárias - InfoPen. Recuperado em http://www.justica. gov.br/news/mj-divulgara-novo-relatorio-do-infopen-nesta-terca-feira/relatorio-depen-versao-web.pdf

Ministério da Saúde, Departamento de Ações Programáticas Estratégicas. (2009). Política Nacional de Atenção Integral à Saúde do Homem: Princípios e Diretrizes.

Miskolci, R. (2009, jun.). A Teoria Queer e a Sociologia: O desafio de uma analítica da normalização. Sociologias, 29. Recuperado em http://www. scielo.br/scielo.php?script=sci_arttext\&pid=S1 $5174522200900010008 \& \operatorname{lng}=\mathrm{en} \& \mathrm{nrm}=$ iso

Nardi, H. (2003). A propriedade social como suporte da existência: A crise do individualismo moderno e os modos de subjetivação contemporâneos. Psicologia \& Sociedade, 1(15), 37-56.

Nardi, H. (2006). A naturalização do discurso liberal: Riscos da privatização do público. In P. Spink \& M. J. Sipnk (Eds.), Práticas cotidianas e a naturalização da desigualdade: Uma semana de notícias nos jornais (pp. 165-188). São Paulo, SP: Cortez.

Nardi, H. C. O. (1998). Ethos masculino e o adoecimento relacionado ao trabalho. In L. F. D. Duarte \& O. F. Leal (Eds.), Doença, sofrimento, perturbação: Perspectivas etnográficas (pp. 95-100). Rio de Janeiro, RJ: Editora Fundação Oswaldo Cruz.

Oliveira, P. P. de. (1998, jan.). Discursos sobre a Masculinidade. Estudos Feministas, 6(1), 91. Recuperado em https://periodicos.ufsc.br/index. $\mathrm{php} / \mathrm{ref} /$ article/view/12036

Oliveira, P. P. (2004). A construção social da masculinidade. Belo Horizonte, MG: Editora da Universidade Federal de Minas Gerais.

Parada, M. (2006). Corpos físicos como corpos cí- 
vicos: Práticas desportivas e educação física no Brasil sob o Estado Novo. In F. C. T. Silva \& R. P. Santos (Eds.), Memória Social dos esportes: Futebol e Política: A construção de uma identidade nacional. Rio de janeiro, RJ: Mauad.

Perrot, M. (2005). As mulheres ou os silêncios da história. Bauru, SP: Edusc.

Pinheiro, C. (2002). No governo dos mundos: Escravidão, contexto coloniais e administração de populações. Estudos Afro-Asiáticos, 24(3). doi: http://dx.doi.org/10.1590/S0101$-546 \mathrm{X} 2002000300001$

Ponte, C. F., \& Reis, J. (2010). Saúde Pública e medicina previdenciária: Complementares ou excludentes. In C. F. Ponte (Ed.), Na corda bamba de sombrinha: A saúde no fio da história (pp. 113-150). Rio de Janeiro, RJ: Editora Fundação Oswaldo Cruz.

Porto, A. (2008, dez.). O sistema de saúde do escravo no Brasil do século XIX: Doenças, instituições e práticas terapêuticas. História, Ciências, Saúde-Manguinhos, 13(4). doi: http://dx.doi. org/10.1590/S0104-59702006000400013

Prins, B., \& Meijer, I. C. (2002). Como os corpos se tornam matéria: Entrevista com Judith Butler. Estudos Feministas, 10(1), 15.

Ribeiro, A. A. (2016). Homens Negros, Negro Homem: A perspectiva de um feminismo negro. Revista de Estudos e Investigações Antropológicas, 2(2).

Sant'anna, M. A. (2002). De um lado, punir, de outro, reformar: Projetos e impasses em torno da implantação da Casa de Correção e do Hospício de Pedro II no Rio de Janeiro (Dissertação de mestrado, Universidade Federal do Rio de Janeiro, RJ, Brasil).

Santos, M. S. (2009). Os Porões da República - A barbárie nas Prisões da Ilha Grande: 18941945. Rio de Janeiro, RJ: Garamond.

Santos, W. G. dos. (1979). Do Laissez-faire repressivo à cidadania em recesso. In W. G. dos Santos (Ed.), Cidadania e justiça (pp. 64-75). Rio de Janeiro, RJ: Campus.

Santos, W. G. (1987). Cidadania e Justiça: A política social na ordem brasileira. Rio de Janeiro, RJ: Campus.

Seffner, F. (2011). Um bocado de sexo, pouco giz, pouco giz, quase nada de apagador e muitas provas: Cenas escolares envolvendo questões gê- nero e sexualidade. Estudos Feministas, 19(2), 561-588. doi: http://dx.doi.org/10.1590/S0104-026 X201100020001

Silva, A. M. de C. e. (2012). Do império à república considerações sobre a aplicação da pena de prisão na sociedade brasileira. Revista EPOS, 3(1). Recuperado em http://pepsic.bvsalud.org/scielo. php?script $=$ sci_arttext\&pid $=$ S2178700X20120 $00100004 \& \operatorname{lng}=\mathrm{pt} \& \operatorname{tlng}=\mathrm{pt}$

Silva, C. C. R. (2013). A aliança entre justiça e psiquiatria no controle do uso de droga: Medicalização e criminalização na berlinda. Revista EPOS, 4(1). Recuperado em http://pepsic.bvsalud. org/scielo.php?script=sci_arttext\&pid=S2178$-700 \times 2013000100004$

Souza, J. (2011). A ralé brasileira: Quem é e como vive. Belo Horizonte, MG: Editora Universidade Federal de Minas Gerais.

Souza, R. M. (2009, jul.-dez.). As representações do homem negro e suas conseqüências. Revista Fórum Identidades, 6.

Stepan, N. L. (2004). Eugenia no Brasil, 1917-1940. In G. Hochman \& D Armus (Eds.), Cuidar, controlar, curar: Ensaios históricos sobre saúde e doença na América Latina e Caribe: História e Saúde (pp. 330-391). Rio de Janeiro, RJ: Editora Fundação Oswaldo Cruz.

Tavares, G. M. (2011). O dispositivo da criminalidade e suas estratégias. Fractal: Revista de Psicologia, 23(1), 123-136. doi: http://dx.doi. org/10.1590/S1984-02922011000100009

Teixeira, R. P. (2014). Cidadania, Estado e estratos marginalizados: A produção da desigualdade social no Brasil em perspectiva histórica. In Anais $23^{\circ}$ EAIC - Encontro Anual de Iniciação Científica. Londrina, PR.

Tittoni, J. (1994). Subjetividade e trabalho. Porto Alegre, RS: Ortiz.

Veiga-Neto, A. (2010). Biopoder e dispositivos de normalização: Implicações educacionais. In Anais XI Internacional IHU: O (des)governo biopolítico da vida humana (pp. 10-24). São Leopoldo, RS: Casa Leiria.

Vigoya, M. V. (2007). Discriminación racial, intervención social y subjetividad. Reflexiones a partir de un estudio de caso en Bogotá. Revista de Estudios Sociales/Journal of Social Studies, (27), 106-121.

Wacquant, L. (2003). Toward a dictatorship over the 
poor? Notes on the penalization of poverty in Brazil. Punishment \& Society, 5(2), 197-205.

Wacquant, L. (2008). O corpo, o gueto e o Estado penal: Entrevista com Loïc Wacquant. Etnográfica, 12(2). doi: 10.4000/etnografica.1811

Wacquant, L. (2013). Punir os pobres: A nova gestão da miséria nos Estados Unidos (3. ed.). Rio de Janeiro, RJ: Revan.

Waiselfisz, J. (2012). Mapa da violência 2012. Os jovens do Brasil. São Paulo, SP: Instituto Sangari.

Welzer-Lang, D. (2001). A construção do masculino: Dominação das mulheres e homofobia. Estudos Feministas Pagu, 2.
Welzer-Lang, D. (2004). Os homens e o masculino numa perspectiva de relações sociais de sexo. In R. Sechupum (Ed.), Masculinidades. São Paulo, SP: Boitempo.

Xavier, V. B. (2010). Os Brasis de Monteiro Lobato: De Jeca Tatu ao Desencantamento (Dissertação de mestrado, Universidade Federal do Paraná, Curitiba, PR, Brasil).

Recebido: $31 / 10 / 2016$

$1^{a}$ revisão: $30 / 10 / 20017$

Aceite final: $31 / 10 / 2017$ 